\title{
MANDATOS COLETIVOS E COMPARTILHADOS NO PODER LEGISLATIVO: potencialidades de inovação democrática e propostas de regulação.
}

\section{Alexandre Montagna Rossini ${ }^{1}$}

\section{Resumo}

Como inovação democrática, tem-se observado o expressivo crescimento das candidaturas coletivas ou compartilhadas em todas as regiões do país. Mediante uma pesquisa bibliográfica e descritiva, analisando as atuais propostas de regulação e algumas dessas experiências mais significativas, à luz do significado da palavra democracia, objetivou-se responder a duas questões principais: essas inovações democráticas têm potencial de mudança na participação política dos representados em relação aos mandatos legislativos de seus representantes, e consequentemente, potencial de mudança do cenário elitizado da política brasileira? $\mathrm{E}$ as atuais propostas de regulação atendem, facilitam ou dificultam a realização dessas potencialidades?

Palavras-chaves: democracia; mandatos coletivos; mandatos compartilhados; participação política; regulação.

\section{COLLECTIVE AND SHARED MANDATES IN THE LEGISLATIVE POWER: potential for democratic innovation and regulatory proposals.}

\begin{abstract}
As a democratic innovation, had been observed an expressive growth of collective and shared candidacies in all country regions. Through a bibliographical and descriptive research, analyzing the current regulation proposals and some of these most significant experiences, from the point of view of the word democracy meaning, the objective was to answer two main questions: do collective and share candidacies have the potential to change the political participation of those represented by these legislative mandates, consequently, potential to change the elitist scenario of Brazilian politics? And do current regulatory proposals answer, facilitate or hamper the realization of these potentials?
\end{abstract}

Keywords: democracy; collective mandates; shared mandates; political participation; regulation.

\footnotetext{
${ }^{1}$ Graduado em Direito pela Universidade de Marília - UNIMAR, mestre em Direito - Teoria do Direito e do Estado pelo Centro Eurípedes de Marília - UNIVEM, professor efetivo do Instituto Federal de Educação, Ciência e Tecnologia de São Paulo - IFSP desde 2011 e doutorando pela UNIMAR. CV: http://lattes.cnpq.br/9722429361008858 Endereço: Rua Angelo Antonio Colafemina, 383, casa 29, Bonfim Paulista, Ribeirão Preto, SP, CEP 14110-000, E-mail: alerossini11@gmail.com
} 


\section{Introdução}

As discussões cotidianas e rasas sobre democracia, por sua natureza de senso comum, acrítica, não permitem às pessoas a percepção de que estão consumindo significados cuidadosamente programados e disseminados por especialistas de diversas áreas, para incutir um sentido meramente instrumental, desprovido de conteúdo, que gera a sensação de conhecimento de causa. A democracia fica reduzida a um procedimento tautológico de criação e aplicação das normas pela e para as elites governantes, de modo que a corrupção e a discrepância da atuação política dos representantes do povo em relação aos interesses reais deste são corolários irresistíveis (ROSENMANN, 2007).

A clássica concepção de democracia representativa estaria, pois, desacreditada, e aos eleitores restaria apenas a tentativa de escolha do candidato "menos ruim". Aumenta a necessidade de maior participação popular nas decisões políticas, e a partir dos anos 1960 e 1970 cresce a ideia de que os cidadãos são capazes de compreender e podem se interessar pelo processo político, podem aprender com a participação na tomada de decisões, a discernir entre seus impulsos e desejos particulares e seu papel de cidadão público. Na década de 1990, passa-se a considerar a democracia mais por seu caráter deliberativo, valorizando o pluralismo cultural e social, seus conflitos e processos comunicativos para mudar os espaços da democracia, do Estado para a sociedade, para a relação discursiva entre representantes e representados (MONTEIRO; MOURA; LACERDA, 2015).

Isso implica a necessidade de uma postura ativa dos cidadãos, construindo uma política humanitária, suprapartidária, comprometida com os problemas globais, considerando a complexidade das situações, pensamentos amplos ao invés dos fragmentados, reconhecimento do que há de melhor nas diversas culturas e regiões, desenvolvimento da solidariedade (MORIN, 2013).

Uma alternativa que tem se destacado no cenário político brasileiro são os chamados mandatos coletivos ou compartilhados, que consistem na divisão do poder decisório do parlamentar eleito com alguns ou até centenas de coparlamentares, cidadãos que o apoiaram desde a campanha ou somente após o êxito eleitoral, que participarão continuamente das tomadas de decisões de seus representantes do Poder Legislativo, de forma presencial ou por meio de aplicativos que permitem contatos remotos, conforme estrutura de trabalho prometida e implementada pelo (s) idealizador (s) do mandato plural. Considerando todas as esferas 
legislativas do país, atualmente somam-se 423 candidaturas e 54 mandatos coletivos ou compartilhados eleitos e distribuídos por todas as regiões do Brasil e as ideologias políticas (SECCHI et al, 2020).

Quanto aos principais modelos, tem-se: os mandatos coletivos em sentido estrito, que se constituem de poucas pessoas, entorno de uma ideologia política ou por algumas pautas específicas desde a fase pré-eleitoral e permitem debates amplos na busca de consensos, muitas vezes tomados em reuniões presenciais; os mandatos compartilhados, que embora surjam da iniciativa e promessa de um candidato de dividir seu poder parlamentar com tantos quantos coparlamentares tiverem interesse, geralmente acima de 100 pessoas, independem de ideologias políticas e suas decisões são tomadas por meios eletrônicos genéricos ou próprios do parlamentar, tendo cada interessado o mesmo peso de voto (SILVA; SECCHI; CAVALHEIRO, 2021).

Ainda não regulados pelo direito positivo brasileiro, tramita no Congresso Nacional uma Proposta de Emenda Constitucional e dois Projetos de Leis: a primeira para inserir a possibilidade de mandatos coletivos em sentido geral no texto constitucional; um Projeto para regular sucintamente o registro da candidatura e a diretriz geral de sua campanha; e o segundo Projeto disciplinando o exercício dos mandatos. (CÂMARA DOS DEPUTADOS 2019; CÂMARA DOS DEPUTADOS 2020a; CÂMARA DOS DEPUTADOS, 2020b).

Relevante analisar tais propostas de regulação em comparação a diversas experiências de mandatos coletivos ou compartilhados relatados por diversos autores, e à luz do significado da palavra democracia, mediante pesquisa bibliográfica e descritiva cujo objetivo é tentar responder a duas questões centrais: se tais mandatos têm potencial de mudança na participação política dos representados em relação aos mandatos legislativos de seus representantes, consequentemente, o potencial de mudança no cenário elitizado da política brasileira; e se as atuais propostas de regulação atendem, facilitam ou dificultam a realização dessas potencialidades.

\section{Referencial Teórico - a democracia.}

Uma palavra muito ouvida e desacreditada da atualidade brasileira é democracia; discursos desesperançosos e/ou totalitários, os chamados votos de protesto, a desfiliação partidária e a abstenção nos pleitos eleitorais indicam isso. Frequentes denúncias de 
corrupção, o "fim" da operação "lava-jato" e, talvez com peso maior, o abismo existente entre as deliberações parlamentares e os interesses de seus representados podem ser causas desse descrédito (SILVA; SECCHI; CAVALHEIRO, 2021).

Outra provável causa não comumente tratada interessa no momento, a disputa pelo significado da palavra "democracia”. Segundo Marcos Roitman Rosenmann (2007), trata-se de uma disputa teórica e política muito importante; comumente, lança-se o termo como objeto de consumo, que projetará uma ideia de organização da vida cotidiana, com significado raso e de fácil assimilação, dissociado das ideias de capitalismo e neoliberalismo; dissemina-se de forma rápida, exaustiva e eficiente, por meios e mentes especializados, de maneira que as pessoas a consumam como um produto seu qualquer.

A democracia representativa segue a mesma lógica: sem a efetiva participação popular, tem-se a "festa" das campanhas eleitorais, reduzida à disputa pelo controle das instituições, produzindo um círculo vicioso de criação e aplicação das normas pela e para as elites governantes; a corrupção não é vista como delito político, sistêmico, e sim como um desvio individual; e a democracia se torna apenas um instrumento ou procedimento complexo, reproduzida por novos meios e conceitos fabricados para a manutenção da ordem vigente, a exemplo do que têm acontecido nas redes sociais. "Cuanto más se predica vivir em sociedades democráticas más se degrada la condición humana" (ROSENMANN, 2007, p. 9).

O que se deveria entender por democracia? Uma via de resposta pode ser mencionar as concepções teóricas da história recente e da atualidade. Segundo Monteiro, Moura e Lacerda (2015), Joseph Shumpeter escreveu em 1940, inspirado na concepção burocrática de Max Weber, que o termo deve ser entendido como um método para a escolha dos líderes políticos, ou seja, teria somente caráter instrumental, encerrando-se nas eleições sazonais. Esta concepção está inserida na chamada teoria da democracia competitiva ou procedimental e minimalista, não possuindo valor substantivo significativo devido à quase inexistência de participação popular e de capacidade de construção coletiva de opiniões e decisões.

Como modelo alternativo ao representativo, que não observa na competição eleitoral a existência de grupos dominantes e assimetrias socioeconômicas, a partir das décadas de 1960 e 1970, entra em cena o formato participativo, com fulcro no sentido originário do termo democracia - governo do povo, resgatando noções como as de bem comum, igualdade e soberania popular, e, sobretudo, combatendo a ideia de que os cidadãos são incapazes ou

\footnotetext{
Revista de Movimentos Sociais e Conflitos | e-ISSN: 2525-9830 | Encontro Virtual | v. 7 | n. 2 |

p. $40-57$ | Jul/Dez. 2021.
} 
desinteressados do processo político, acrescentando um aspecto pedagógico fundamental: “como resultado da sua participação na tomada de decisões, o indivíduo é ensinado a distinguir entre seus próprios impulsos e desejar, aprendendo a ser tanto um cidadão público, quanto privado" (PATEMAN, 1992 apud MONTEIRO; MOURA; LACERDA, 2015, p. 163)

Citado por Pestana e Oliveira (2010), Macpherson elaborou um percurso de construção do modelo de democracia participativa, a saber:

1) o afastamento da ideologia burguesa; 2) o distanciamento da divisão capitalista de classes; 3) a retomada em direção ao humanismo marxista; 4) o retorno ao conceito rousseauísta de sociedade, lembrando o conceito de vontade geral; 5) a recuperação de um senso de comunidade mais forte do que temos. (MACPHERSON, 1978 apud PESTANA; OLIVEIRA, 2010, p. 2)

Remando contra a onda hegemônica da democracia procedimental, haveria mudança de locus, do Estado para a sociedade, sem romper com o tradicional sistema representativoeleitoral para passar à democracia direta, mas ampliando os espaços de atuação dos cidadãos.

De agora em diante, quando nos colocamos os problemas de saber se houve desenvolvimento da democracia na Itália durante os últimos anos, deveremos procurar ver não o número de eleitores, mas o espaço no qual o cidadão pode exercer seu próprio poder de eleitor. Podemos assim considerar como reforma democrática nesta direção a que institui os conselhos escolares com a participação de representantes dos pais (BOBBIO, 1997, p. 55)

Evoluindo nesse sentido, a partir da década de 1990 passou-se a considerar a democracia mais por seu aspecto ou conceito deliberativo, na linha do filósofo alemão Jürgen Habermas, que se valeu do pluralismo cultural e social e seus conflitos de interesses para mudar o foco da democracia para os espaços públicos e para os procedimentos comunicativos, defendendo que é na interação discursiva dos cidadãos e seus representantes que estaria o ponto nevrálgico da construção das decisões políticas, processo que propiciaria o reconhecimento dos direitos e reivindicações individuais. (MONTEIRO; MOURA; LACERDA, 2015)

A democracia deliberativa, contando com a participação da sociedade civil nas discussões racionais em ambientes / espaços públicos compreenderia novos temas, consideraria pessoas ligadas de forma mais próxima aos problemas sociais, pessoas diversas e não atreladas a instituições estatais e econômicas e a seus respectivos vieses. 
Contudo, devido às complexas conexões dos subsistemas sociais, especialmente, nesse caso, o econômico e o político, colocam em risco o processo comunicativo, que é influenciado ou mesmo controlado por meio do dinheiro e da burocracia, desvirtuando as necessidades da sociedade civil pelos interesses pessoais em ter e poder, sacrificando os aspectos humanos que não contribuem para sua lógica competitiva, a solidariedade e do bemestar existencial.

Segundo Edgar Morin (2013), complexidade compreende todos os segmentos da vida cotidiana, da cidade e do campo, os comportamentos individuais e de grupos, seus estilos de vida, políticas públicas e ações privadas em prol de comunidades. É preciso considerar todos esses dados particulares em direção aos conjuntos que constituem e viceversa, trabalhando dialeticamente suas causas e suas consequências, verificando as possibilidades de mudanças e os objetivos pretendidos.

É preciso construir uma política humanista, que reflita sobre o paradoxo do desenvolvimento, que produz aspectos negativos ao mesmo tempo que realiza o crescimento econômico, técnico e científico que tantos benefícios proporcionam a boa parte da humanidade. Assim, a política deveria atuar para viabilizar regramentos e ações conforme as necessidades de cada país ou região, crescendo onde deve crescer, decrescendo onde for necessário. Contudo, "atualmente, o pensamento político encontra-se no grau zero. Ele ignora os trabalhos sobre o devir das sociedades e sobre o devir do mundo." (MORIN, 2013, p. 55)

Sem uma mudança de paradigma político, que propicie condições para que as pessoas vivam de forma mais plena, salvaguardando o melhor de cada cultura, privilegiando o qualitativo ao invés do quantitativo, sem tal mudança, as resistências privadas, isoladas, parecem ser incapazes de mudanças significativas em âmbito coletivo.

Contudo, os ânimos parecem contentar-se com a disputa ideológica direita-esquerda, e mais com o significado emotivo destes termos do que com o significado descritivo (BOBBIO, 1995). Identificam-se com seus valores, muitas vezes comuns a ambos, embora

a direita como forças sociais pró capitalismo, cujas práticas políticas e orientação ideológica possuem o intuito de manter as estruturas econômicas, políticas, culturais e morais que favorecem a reprodução desse sistema. Historicamente, o conservadorismo e o liberalismo e suas variantes dominam esse campo. Já a esquerda na sociedade moderna capitalista comporta as forças sociais que disputam a direção das massas com vistas a um projeto societário socialista construído por e em prol da classe trabalhadora (PEREIRA, 2019, p.81). 
O pensador revolucionário Félix Guattari (2001) enfatiza a necessidade de mudança de postura dos cidadãos, no sentido de serem mais ativos em todos os segmentos sociais, inclusive na política. Valorizando a necessidade de se trabalhar a subjetividade, o autor explica que se deve superar as influências das grandes mídias que homogeneízam e servem ao capitalismo; superar as antigas lutas de classes pelas discussões de questões transversais que respeitem as singularidades e heterogeneidades, mediante novas práticas micropolíticas e microssociais.

No mesmo sentido, Pestana e Oliveira (2010) lembram que, para Macpherson, uma piora na qualidade de vida gerada pelo crescimento econômico pode fazer as pessoas criarem uma certa consciência do interesse público distinta dos interesses privados de cada consumidor e dos interesses das elites políticas que disputam o controle da máquina pública.

Vê-se a importância da luta teórica e prática / comunitária como projeto alternativo de democracia; ela deve ser concebida como prática social e plural do poder. "Descartada la democracia como forma de vida, transmutan la noción de bien común que la acompanha." (ROSENMANN, 2007, p. 13)

\section{Mandatos Coletivos e Compartilhados}

Analisando a crise política atual, a descrença na democracia representativa, Silva, Secchi e Cavalheiro (2021) acreditam tratar-se de crise da representação dos interesses dos cidadãos, devido à disparidade entre os anseios do eleitor e as ações dos seus representantes eleitos. Uma alternativa que tem ganhado notoriedade é a participação contínua dos cidadãos nas tomadas de decisões de seus representantes do Poder Legislativo, sobretudo na esfera municipal, seja na proposição e votação de projetos de leis, seja em posicionamentos políticos específicos, ideológicos e diversos. Os chamados mandatos coletivos e os mandatos compartilhados.

De fato, nota-se um crescimento vertiginoso desses mandatos se comparado o último pleito municipal aos anteriores: a primeira experiência ocorreu em 1994, mas novos casos só apareceram em 2010, totalizando quatro, todas as candidaturas sendo eleitas; em 2014 candidataram-se 74 e foram eleitos 18; e em 2018 foram eleitos 28 dentre as 341 candidaturas. Considerando todas as esferas legislativas do país, atualmente somam-se 423 
candidaturas e 54 mandatos coletivos ou compartilhados eleitos e distribuídos por todas as regiões do Brasil e as ideologias políticas (SECCHI et al., 2020).

Até hoje, o maior número de candidaturas coletivas e compartilhadas ocorreu na região Sul, com 44, apesar de somente seis terem sido eleitas; no Sudeste, das 43 candidaturas, 18 triunfaram nas eleições; no Nordeste, contam-se 13 candidaturas e 7 eleitos; por fim, nas regiões Centro-Oeste e Norte foram apenas 7 e 3 candidaturas, respectivamente, com apenas uma eleita em Alto Paraíso de Goiás. As iniciativas dessas candidaturas não são dos partidos políticos, mas 22 dos 35 partidos aceitam-nas e de fato as têm ou tiveram, destacando-se com maiores frequências a REDE, o PSOL, o PT e o PSB, e com menor frequência o PR, o PROS, o PC do B, o PSL, o PMN e o PPS. A preponderância da esquerda e centro-esquerda é de $47 \%$ (RAPS, 2019).

Para caracterizar os mandatos, principalmente em coletivos ou compartilhados, podese utilizar as dez dimensões analíticas adotadas pela Rede de Ação Política pela Sustentabilidade - RAPS $(2019)^{2}$, quais sejam: iniciativa, tamanho, elegibilidade, acesso, permanência, distribuição do poder, escopo do compartilhamento, partilha de custos e benefícios, processo de tomada de decisão e mecanismo de interação. Passa-se a esclarecer resumida e objetivamente cada uma delas.

Iniciativa refere-se aos autores ou ao autor da proposta, se partiu de um grupo de pessoas ou de indivíduo; tamanho visa contabilizar o número de coparlamentares; elegibilidade estabelece os requisitos para a participação das pessoas do grupo, podendo compreender domicílio eleitoral, conhecimento técnico, afinidade ideológica dentre outros; acesso identifica o momento do início da participação dos coparlamentares, se desde a campanha eleitoral, do início do mantado ou em seu curso.

Permanência implica as regras para manutenção ou não da condição de coparlamentar, tais como assiduidade e cumprimento das funções que lhe forem designadas. distribuição do poder entre o parlamentar oficialmente eleito e seus colaboradores, podendo ser igualitário ou não, expresso em percentual ou simples soma de votos etc.; escopo do compartilhamento delimita em quais situações os coparlamentares podem exercer eu poder,

2 A Rede de Ação Política pela Sustentabilidade - RAPS constitui-se de uma organização suprapartidária, fundada em 2012, que atua para reunir, capacitar a apoiar novos líderes políticos abertos ao diálogo, à transparência e ao desenvolvimento sustentável (RAPS, 2019). 
por exemplo, se em todas as decisões, se somente em decisões preliminares, referentes a comissões ou assuntos específicos.

Partilha de custos e benefícios podem envolver desde o mandato até peculiaridades do exercício do mandato, como verbas de gabinete, salários, despesas com viagens e muitas outras; processo de tomada de decisão implicando a busca por consenso ou a simples votação, ou ambas conforme os tipos de decisões; e, finalmente, o mecanismo de interação entre os coparlamentares, que pode envolver diversos tipos de tecnologias da informação ou a tradicional reunião presencial.

Essa inovação democrática, por compreender alternativa ao modelo tradicional de exercício do mandato, não obstante possa assumir variados nomes, formatos e amplitudes em seu modus operandi, implica, fundamentalmente, efetiva divisão do poder decisório do parlamentar eleito com seus apoiadores, não limitando-se a meras consultas de opiniões. Assim, tem como elementos básicos o parlamentar eleito, ao menos um coparlamentar e o compromisso formal ou informal que vem sendo chamado de estatuto do mandato (RAPS, 2019).

Além da diversidade de nomenclaturas, tais como mandatos colaborativos, participativos, cooperativos ou cidadanistas, ora resumidas em coletivos e compartilhados, as possibilidades de funcionamento são muitas, haja vista não existir qualquer definição de modelo, podendo haver variações em qualquer das dez dimensões acima apresentadas, conforme a compreensão das partes envolvidas, os acertos e erros observados nos diversos casos existentes. Essa liberdade pode ser vista como algo bastante positivo, no sentido da criatividade e possibilidade de adequação às necessidades e interesses de cada situação.

Segundo os autores Silva, Secchi e Cavalheiro (2021), os mandatos coletivos costumam constituir-se de poucas pessoas, que se unem desde a campanha por uma ideologia política ou por algumas pautas específicas, como a defesa de minorias excluídas ou dos direitos dos animais não-humanos; seus tamanhos reduzidos permitem debates amplos e busca de consensos, muitas vezes tomados em reuniões presenciais.

Ao contrário, e de acordo com os mesmos autores (SILVA; SECCHI; CAVALHEIRO, 2021), os mandatos compartilhados surgem principalmente da iniciativa e promessa de um candidato de dividir seu poder parlamentar com tantos quantos coparlamentares tiverem interesse, geralmente acima de 110 pessoas, independentemente de 
suas ideologias políticas; as decisões são tomadas por meios eletrônicos genéricos ou próprios do parlamentar, nos quais cada interessado tem o mesmo direito de votar nas questões por ele trazidas.

O caso pioneiro de mandato coletivo é o do deputado estadual Durval Ângelo do PT de Minas Gerais, que utiliza este modelo desde 1994 e teve seis mandatos consecutivos. O deputado criou Conselhos Políticos espalhados por diversas regiões do Estado para, presencialmente, planejarem, analisarem e encaminharem propostas, bem como deliberarem sobre todas as decisões relevantes, variando de 20 até 50 o número de coparlamentares. Várias outras experiências contam com um número bem reduzidos de coparlamentares (RAPS, 2019).

Um exemplo interessante de caso de mandato compartilhado é o do vereador Gabriel Azevedo, do PHS, eleito em 2016 com 10.185 votos para o cargo de vereador no município de Belo Horizonte - MG. A iniciativa foi dele, que propôs dividir seu poder decisório com todos os seus eleitores que tivessem domicílio eleitoral por meio de um aplicativo, o Meu Vereador. Até o final de seu primeiro mandato em 2020, pois foi reeleito neste mesmo ano, 1700 coparlamentares acessavam seu aplicativo cotidianamente para votar nos assuntos, com o mesmo peso decisório entre todos eles (SILVA; SECCHI; CAVALHEIRO, 2021).

\section{Proposta de regulação}

Como visto, embora existam na prática política e cada vez em maior número, os mandatos coletivos e compartilhados não estão previstos no Direito Positivo Brasileiro. Por se tratar de setor do Direito Público, o Direito Eleitoral segue o princípio da legalidade estrita, de modo que só está legitimado ou reconhecido pelo Ordenamento Jurídico o que nele estiver expressamente previsto.

Esta situação marginal ou não institucional pode gerar insegurança jurídica, tanto para o parlamentar eleito, quanto para os coparlamentares, como também aos seus apoiadores, pois eventuais conflitos de interesses entre eles não encontrarão respaldo em registro eleitoral ou documento formal oficializado e apto a gerar efeitos jurídicos ensejadores de tutela jurisdicional específica.

Exemplificando: se o parlamentar eleito descumprir o compartilhamento do poder decisório previamente avençado, alguma etapa de seu procedimento deliberativo ou mesmo a 
divisão dos recursos próprios do mandato, seus coparlamentares ou quiçá seus apoiadores não estarão legitimados a proporem ação judicial apta a produzir efeitos na esfera eleitoral; se um coparlamentar não desempenhar as funções assumidas ou cometer algum ato ilícito no exercícios delas, da mesma forma o parlamentar, embora possa agir arbitrariamente, não terá os meios que gostaria para resolver a questão; por fim, a insegurança para os apoiadores nasce antes mesmo da eleição de seu representante, tendo que se contentar com a palavra do candidato.

\subsection{Proposta de Emenda Constitucional - PEC 379/2017}

No dia 09 de novembro de 2017, a Deputada Renata Abreu do PODE-SP apresentou Proposta de Emenda Constitucional - PEC visando acrescentar parágrafo ao art. 14 da Constituição Federal para institucionalizar o mandato coletivo no âmbito do Poder Legislativo. Bastante simples, ficaria assim: “Art. 14, § 12. Os mandatos, no âmbito do Poder Legislativo poderão ser individuais ou coletivos, na forma da lei.” (BRASIL, 2017).

A parlamentar inicia a justificativa da proposta afirmando que "No momento em que o País enfrenta grave crise ético-política, consideramos necessário rever nosso sistema eleitoral e representativo, com vistas a ampliar a participação da sociedade nas decisões políticas." (BRASIL, 2017) E complementa seu entendimento de que os mandatos coletivos podem dar força à participação popular na política e expandir o conceito de representação política.

A proposta foi devolvida pelo relator sem manifestação, Deputado Chico Alencar do PSOL-RJ, e arquivada em 21 de janeiro de 2019; foi desarquivada e teve como último despacho, em 02 de julho do mesmo ano, o envio à Comissão de Constituição e Justiça e de Cidadania - CCLJC, e nova nomeação de relatoria, a Deputada Shéridan do PSDB-RR, atualmente aguardando apreciação do plenário. (CÂMARA DOS DEPUTADOS, 2019)

\subsection{O Projeto de Lei $n^{\circ} 4475 / 2020$ - o registro eleitoral e a propaganda política}

O primeiro projeto, PL $\mathrm{n}^{\mathrm{o}} 4475$ de 10 de setembro de 2020, de autoria do Deputado João Daniel do PT-SE, pretende regular, ainda que sucintamente, o registro de candidaturas coletivas ao Poder Legislativo e as suas propagandas eleitorais. O faz propondo alterar a Lei 
$\mathrm{n}^{\circ}$ 9.504, de 30 de setembro de 1997, para acrescentar aos artigos 12 e 36 parágrafo sexto, respectivamente com os seguintes teores:

Art. $12, \S 6^{\circ}$ No caso de candidaturas promovidas coletivamente, o candidato poderá indicar, no pedido de registro, o nome do grupo ou coletivo social que o apoia, que será acrescido ao nome registrado pelo candidato, desde que não se estabeleça dúvida quanto à identidade do candidato registrado, sendo vedado o registro apenas do nome do respectivo grupo ou coletivo social."

Art. 36, $\S 6^{\circ}$ A propaganda de candidaturas promovidas coletivamente deverá indicar, de forma inequívoca, o candidato registrado, e, facultativamente, o grupo ou coletivo social que o apoia e seus apoiadores, desde que não se estabeleça dúvida quanto à identidade do candidato registrado, sendo vedada a menção à candidatura e o pedido de voto ou de apoio eleitoral a terceiro não registrado como candidato. (BRASIL, 2020a)

Como se depreende da leitura dos textos acima, a ideia do proponente é simplesmente ressalvar que tanto o registro quanto a propaganda ficam vinculadas ao nome do candidato ao cargo, podendo, apenas, mencionar o nome do grupo ou coletivo social de forma acessória.

A proposta chegou à Comissão de Constituição e Justiça e de Cidadania - CCJC em 10 de fevereiro de 2021 e aguarda designação de relator, não havendo qualquer nova ação legislativa registrada no site oficial da Câmara dos Deputados que, inclusive, informa não haver tramitação no Senado Federal nem na Presidência da República. (CÂMARA DOS DEPUTADOS, 2020a)

\subsection{O Projeto de Lei $n^{\circ} 4724 / 2020$ - o exercício do mandato coletivo}

Mais completo é o projeto que pretende regular o exercício do mandato coletivo no Poder Legislativo, apresentado pelo Deputado André Figueiredo do PDT-CE em 25 de setembro de 2020 e apensado aos autos do projeto anterior em 21 de dezembro do mesmo ano (CÂMARA DOS DEPUTADOS, 2020b).

Com 16 artigos, o projeto pretende regular o mandato coletivo, nomenclatura que esclarece compreender todos aqueles que forem exercidos de forma coletiva, compartilhada, colaborativa, cooperativa ou participativa, no âmbito das três esferas legislativas, municipal, estadual e federal.

Da mesma forma que o PL 4475/2020, estabelece que as prerrogativas e obrigações do cargo ficam em nome do parlamentar eleito, inovando, porém, ao submeter seu exercício 
aos estritos termos do estatuto do mandato, "acordo formal que delimita os elementos fundamentais do vínculo contratual entre o parlamentar e os coparlamentares" (BRASIL, 2020b, p. 02). Este instrumento deverá ter ampla divulgação e, conforme art. 12 do PL, prever:

I - critérios de distribuição do peso político decisório de cada coparlamentar dentro do mandato; II - critérios objetivos e impessoais para permanência ou desligamento de coparlamentar; III - abrangência do poder decisório compartilhado, com a definição dos tipos de decisão que estarão sujeitas à definição coletiva; IV - critérios de partilha dos custos de campanha e dos benefícios decorrentes do cargo, desde que não sejam de gozo exclusivo do parlamentar; V - processo de tomada de decisão, que contemple a metodologia utilizada para a definição das decisões relativas às matérias legislativas; e VI - mecanismo de interação entre os membros do grupo de mandato coletivo, com a descrição das ferramentas e métodos utilizados. (BRASIL, 2020b, p. 4-5)

Constata-se que o estatuto do mandato é documento fundamental não só para futuras análises de mérito, mas também por ser requisito formal para seu enquadramento no Ordenamento Jurídico posto, o que não acontecerá se não possuir delimitação do quantitativo de coparlamentares e do processo de decisão coletivo estruturado.

Afirmo preliminarmente que o único modo de se chegar a um acordo quando se fala de democracia, entendida como contraproposta a todas as formas de governo autocrático, é o de considerá-la caracterizada por um conjunto de regras (primárias ou fundamentais) que estabelecem quem está autorizado a tomar as decisões coletivas e com quais procedimentos. (BOBBIO, 1997, p. 17)

Dois pontos que se pode considerar excessivamente limitadores são os que tratam do tamanho da chapa, por definir um máximo de cinco pessoas, ou seja, o parlamentar e mais quatro coparlamentares, e sua vinculação a partido político, não apenas na previsão de candidatura da chapa de mandato coletivo, como também seus critérios de participação, que deverão estar previstos no estatuto do partido. Os coparlamentares deverão ser filiados ao partido, pertencerem ao domicílio eleitoral respectivo e serão escolhidos juntamente com os candidatos aos cargos.

\section{Análises da inovação democrática e de sua possível regulação}

O expressivo crescimento das candidaturas coletivas ou compartilhadas e o triunfo eleitoral de várias delas trazem a relevância das análises sobre essa nova forma de representação democrática, sobretudo para se tentar entender duas questões: seu potencial de 
mudança na participação política dos representados em relação aos mandatos legislativos de seus representantes, consequentemente, o potencial de mudança no domínio elitizado da política brasileira; e se as atuais propostas de regulação atendem, facilitam ou dificultam a realização dessas potencialidades.

Este crescimento, principalmente nas eleições municipais, cujos parlamentares deverão atuar mais diretamente na resolução das demandas locais, mais próximas de seus representados, revela que cada vez mais eleitores, especialmente a partir de 2014, não estão satisfeitos com o modelo de democracia representativa tradicional, não se sentem efetivamente contemplados pelos projetos e pelas decisões políticas em seu município, desejando participar mais da vida política local.

Vários casos descritos por Silva, Secchi e Cavalheiro (2021) e outros tantos que se pode conhecer por meio do relatório RAPS (2019), demonstram experiências reais de compartilhamento do poder parlamentar do candidato eleito, desde a elaboração de projetos legislativos, até a definição dos votos nas propostas em plenário, seja no formato coletivo, seja no compartilhado, mas com distinções relevantes e não confrontadas entre os dois.

O modelo coletivo, pelo número reduzido de coparlamentares, permite amplo debate e obtenção de consensos para as tomadas de decisões, cumprindo com o papel pedagógico da democracia participativa e com o processo comunicativo da democracia deliberativa, alhures mencionadas. Por outro lado, por serem poucas as pessoas participando do processo, pode significar apenas e tão somente um aumento do número de representantes, mantendo-se os representados na mesma posição passiva e distante dos debates e decisões políticas.

Por exemplo, o mandato coletivo chamado Gabinetona, junção de duas candidaturas coletivas do município de Belo Horizonte em 2017, das vereadoras Áurea Carolina e Cida Falabella, teve como regra exclusiva para tomada de decisões a deliberação por consenso, e nunca a agregação de votos, por entenderem que só assim haveria realmente representação do coletivo, abstendo-se de decisões quando não se chegava a um consenso. Porém, o grupo de coparlamentares foi fechado no momento da campanha, constituiu-se somente de mulheres vinculadas ao movimento Muitas e afinadas com sua ideologia e suas pautas (SILVA; SECCHI; CAVALHEIRO, 2021).

Já o modelo compartilhado, inversamente, possui um número bem mais elevado de coparlamentares, aumentando expressivamente a participação efetiva dos cidadãos apoiadores 
nas tomadas de decisões do seu representante parlamentar, mas com menos condições de proporcionar um processo comunicativo aprofundado e, consequentemente, não contribuindo tanto quanto o modelo anterior para o aspecto pedagógico político, embora haja debates em vários casos.

Um exemplo foi o mandato compartilhado do vereador Gustavo Bonafé, do PSDB de Poços de Caldas, MG, chamado + Agentes 165, 2017-2020, que criou 12 áreas temáticas de interesse para que os cidadãos discutam, tragam alternativas para resolução dos problemas do município e votem nos temas mais importantes, utilizando o aplicativo WhatsApp para tudo isso. (RAPS, 2019)

Quanto às propostas de regulação ora em trâmite no congresso nacional, difícil opor razão à aprovação da PEC 379/2017 e por três motivos: a objetividade de seu texto, para que somente esteja prevista a possibilidades de mandatos legislativos coletivos, em sentido amplo, no sistema eleitoral brasileiro; por ser alternativa democrática condizente com a evolução do conceito de democracia participativa e deliberativa; e devido à existência de diversos casos exitosos, que têm sido objeto de pesquisas descritivas metodologicamente idôneas, conforme referências bibliográficas ora utilizadas, e que têm apontado positivamente para o aperfeiçoamento e a ampliação dos modelos.

O PL 4475/2020 regularia de forma também simples o registro e campanha das candidaturas coletivas ou compartilhadas, necessitando-se do PL 4724/2020 para complementar a questão do exercício desses mandatos, projeto cujo conteúdo requer maior atenção em dois pontos: previsão do estatuto do mandato e vinculação estrita a partido político.

O primeiro ponto é bastante positivo, tanto para salvaguardar os apoiadores coparlamentares de que as promessas de campanha do parlamentar, principalmente em relação à divisão do poder político decisório, serão efetivamente cumpridas, quanto para os eleitores que terão termos objetivos para decidir sobre seu voto e depois para cobrar o cumprimento por parte de seu candidato.

O segundo ponto, contudo, não condiz com o que se vem praticando ao exigir que os mandatos, seus parlamentares e também os coparlamentares sejam escolhidos dentro dos partidos conjuntamente, além da necessidade de todos terem filiação partidária e estarem 
submetidos às regras do estatuto do partido que poderão tratar de detalhes do exercício do mandato.

Isso significa que, embora o PL esclareça logo de início que abrange todos os tipos de mandatos plurais sob a rubrica de mandatos coletivos, trata apenas destes em sentido estrito, já que, como visto, o formato compartilhado permite um número indefinido de coparlamentares, cujos critérios de inclusão, permanência e exclusão são de livre escolha de cada proposta de mandato, definidos na fase de campanha ou depois da eleição, exigindo ou não afinidade ideológica, por exemplo.

\section{Conclusões}

$\mathrm{Na}$ linha do referencial teórico adotado e dos documentos avaliativos analisados, pode-se concluir que:

Os mandatos coletivos e compartilhados propiciam, tanto na teoria quanto na prática, maior participação política dos cidadãos em relação aos mandatos legislativos de seus representantes, configurando inovação democrática viável em relação ao modelo de democracia representativa tradicional;

O aumento de 4 casos de candidaturas coletivas ou compartilhadas até 2012, para 74 em 2014-2016 com 18 eleitas e para 341 com 28 eleitas em 2018-2020, revela o potencial dessa inovação democrática em melhorar tal participação;

Já o consequente potencial de mudança no domínio elitizado da política brasileira é precipitado afirmar, pois, embora exista na teoria, a proporcionalidade dos triunfos eleitorais até diminuiu de 2014 para 2020 , de $24,32 \%$ para $8,21 \%$;

Aperfeiçoando-se os meios de debates dos mandatos compartilhados, estes parecem ter maior potencial democrático-deliberativo, pela participação de um número maior de coparlamentares no processo comunicacional com seu representante eleito;

As propostas legislativas de regulação, uma vez aprovadas, trarão maior segurança jurídica e ratificarão as principais práticas adotadas até o momento, sobretudo com a exigência de que os mandatos sejam exercidos estritamente de acordo com seu estatuto;

Por outro lado, a regulação proposta refere-se ao modelo coletivo em sentido estrito, preocupando-se com a manutenção da identificação do parlamentar eleito e sua diferenciação 
formal e jurídica em relação aos coparlamentares, e não com o modelo compartilhado e com a preservação da autonomia dos cidadãos em criarem formatos inovadores de mandatos plurais e desvinculados dos ditames partidários.

\section{REFERÊNCIAS}

BOBBIO, Norberto. Direita Esquerda: razões e significados de uma distinção política. Tradução: Marco Aurélio Nogueira. São Paulo: Editora Unesp, 1995. Disponível em: http://www.comtudo.com.br/edicoes/pdfs/bobbio_esquerda_direita.pdf Acesso em: 29 jul 2021.

BOBBIO, Norberto. O Futuro da Democracia: uma defesa das regras do jogo. Tradução: Marco Aurélio Nogueira. 6.ed. São Paulo: Editora Paz e Terra, 1997. Disponível em: https://edisciplinas.usp.br/pluginfile.php/5551654/mod_resource/content/1/Boobio\%2C\%20N orberto $\% 200 \% 20$ futuro $\% 20 \mathrm{da} \% 20$ Democracia $\% 20$ \%20uma\%20defesa\%20das\%20regras\%20do\%20jogo.pdf Acesso em: 26 jul 2021.

BRASIL CÂMARA DOS DEPUTADOS. Projeto de Emenda à Constituição n ${ }^{0}$ 379, de 2017. Insere parágrafo ao art. 14 da Constituição Federal para possibilitar o mandato coletivo no âmbito do Poder Legislativo. Brasília, DF: Câmara dos Deputados, 2017. Disponível em: https://www.camara.leg.br/proposicoesWeb/prop_mostrarintegra?codteor=1620713\&filenam $\underline{\mathrm{e}=\mathrm{PEC}+379 / 2017 .}$. Acesso em 25 jul 2021.

BRASIL. CÂMARA DOS DEPUTADOS. Projeto de Lei ${ }^{\circ} 4475$, de 2020. Altera a Lei ${ }^{\circ}$ 9.504, de 30 de setembro de 1997, para estabelecer regras para o registro e para a propaganda eleitoral de candidaturas promovidas coletivamente. Brasília, DF: Câmara dos Deputados, 2020a. Disponível em:

https://www.camara.leg.br/proposicoesWeb/prop_mostrarintegra?codteor=1928186 Acesso em 25 jul 2021.

BRASIL. CÂMARA DOS DEPUTADOS. Projeto de Lei no 4724, de 2020. Dispõe sobre o exercício coletivo do mandato eletivo no Poder Legislativo. Brasília, DF: Câmara dos Deputados, 2020b. Disponível em:

https://www.camara.leg.br/proposicoesWeb/prop_mostrarintegra?codteor=1932563 Acesso em 25 jul 2021.

CÂMARA DOS DEPUTADOS. Proposta de Emenda à Constituição PEC 379/2017, 2019 Disponível em https://www.camara.leg.br/propostas-legislativas/2162014. Acesso em 25 jul 2021.

CÂMARA DOS DEPUTADOS. Projeto de Lei PL 4475/2020 e seus apensados, 2020a. Disponível em: https://www.camara.leg.br/propostas-legislativas/2262090 Acesso em 25 jul 2021. 
CÂMARA DOS DEPUTADOS. Projeto de Lei PL 4724/2020 e seus apensados, 2020b. Disponível em: https://www.camara.leg.br/propostas-legislativas/2263417 Acesso em 25 jul 2021.

GUATTARI, Félix. As três ecologias. Tradução: Maria Cristina F. Bittencourt. 11.ed. Campinas: Papirus, 2001. Disponível em:

https://edisciplinas.usp.br/pluginfile.php/5290521/mod_resource/content/1/guattari-as-tresecologias.pdf. Acesso em: 22 mar. 2021.

MONTEIRO, Lorena M.; MOURA, Joana T. V. de; LACERDA, Alan D F. Teorias da democracia e a práxis política e social brasileira: limites e possibilidades. Sociologias, v.17, n.38, 2015, p. 156-191.

MORIN, Edgar. A via para o futuro da humanidade. Rio de Janeiro: Bertrand Brasil, 2013.

PEREIRA, Célia B. da S. A atualidade da classificação político-ideológica: esquerda e direita. Vitória: Argumentum, v. 11, n. 1, 2019, p. 69-83. Disponível em:

https://periodicos.ufes.br/argumentum/article/view/19682/16672 Acesso em: 29 jul 2021.

PESTANO, Sdnei Almeida; OLIVEIRA, Neiva Afonso. C. B. MACPHERSON: A BUSCA DE UM MODELO DE DEMOCRACIA. In: Encontro de Pós-Graduação, XII, 2010, Pelotas. Anais eletrônicos... Pelotas, 2010. Disponível em: https://www2.ufpel.edu.br/cic/2010/cd/pdf/CH/CH_00749.pdf Acesso em: 26 jul 2021.

REDE DE AÇÃO POLÍTICA PELA SUSTENTABILIDADE (RAPS). Mandatos coletivos e compartilhados: desafios e possibilidades para a representação legislativa no Século XXI. São Paulo: RAPS, 2019. Disponível em:

https://www.raps.org.br/2020/wpcontent/uploads/2019/11/mandatos_v5.pdf. Acesso em 25 jul 2021

ROSENMANN, Marcos R. Democracia sin democratas y otras invenciones. Madri: Sequitur, 2007.

SECCHI, Leonardo, LEAL, Leonardo, REZENDE, Débora, CAVALHEIRO, Ricardo A., LÜCHMANN, Ligia. As candidaturas coletivas nas eleições municipais de 2020: análise descritiva e propostas para uma agenda de pesquisa sobre mandatos coletivos no Brasil. Brasília: Editora IABS, 2020. Disponível em: https://zenodo.org/record/4423739\#.YQbxxI5KiM8 Acesso em 27 jul 2021.

SILVA, Willian Q. da S.; SECCHI, Leonardo; CAVALHEIRO, Ricardo A. Mandatos coletivos e compartilhados no Brasil: análise descritiva de inovações democráticas no Poder Legislativo. Revista Debates, v. 15, n. 1, p. 168-190, jan.-abril 2021. Disponível em: https://www.seer.ufrgs.br/debates/article/view/110367 Acesso em 24 jul 2021 